\title{
Acute care of older patients in the emergency department: strategies to improve patient outcomes
}

This article was published in the following Dove Press journal:

Open Access Emergency Medicine

4 September 2015

Number of times this article has been viewed

John J McCabe

Sean P Kennelly

Department of Age-Related Health Care, Tallaght Hospital, Dublin, Ireland

Correspondence: Sean P Kennelly Department of Age-Related Health Care, Tallaght Hospital, Tallaght, Dublin 24, Ireland

Email sean.kennelly@amnch.ie

\begin{abstract}
Older patients in the emergency department (ED) are a vulnerable population who are at a higher risk of functional decline and hospital reattendance subsequent to an ED visit, and have a high mortality rate in the months following an ED attendance. The delivery of acute care in a busy environment to this population presents its own unique challenge. The purpose of this review is to detail the common geriatric syndromes encountered in the ED as well as the appropriate strategies and instruments, which can be utilized to support the clinical decision matrix and improve outcomes.
\end{abstract}

Keywords: delirium, dementia, emergency department, comprehensive geriatric assessment

\section{Introduction}

Patients aged 65 years and over account for approximately $20 \%$ of emergency department (ED) presentations. ${ }^{1}$ It is projected that this figure will rise substantially in the coming decades, in line with the demographic trajectory. ${ }^{2}$ In the US, it is predicted that $25 \%$ of Medicare beneficiaries will be aged 85 years and over by $2030 .^{3}$ In 2011 , the British Geriatric Society reported that patients over 65 years constituted over $60 \%$ of hospital admissions, $65 \%$ of bed days, and $70 \%$ of emergency readmissions. ${ }^{4}$ Furthermore, they reported that people with long-term conditions were the major users of care services, making up 55\% of general practitioner visits and $70 \%$ of emergency and outpatient appointments. ${ }^{4}$

The busy environment of the ED is arguably an unsuitable place for care of older patients, ${ }^{3}$ particularly those with delirium or dementia. Older patients are at a higher risk of functional decline and developing medical complications subsequent to an ED visit. ${ }^{5}$ One study reported a mortality rate of $23 \%$ within 6 months in older patients following an ED attendance. ${ }^{6}$ Older patients are more likely to present with a greater level of acuity, ${ }^{7}$ arrive by ambulance,${ }^{8}$ have longer ED stays, ${ }^{8}$ higher rates of admission to hospital ${ }^{9}$ and Intensive Care. ${ }^{10}$ We have previously shown that ED reattendances in older patients are high, with 13\% reattending within 1 month, and almost half reattending within 12 months. ${ }^{11}$

Older patients in the ED are more likely to have complex presentations with multiple comorbidities. The delivery of acute care in a busy environment to this vulnerable population will be an increasingly larger challenge in the future. Therefore, it is important to develop and introduce strategies to improve outcomes in older patients in the ED. This clinical update review details the common geriatric syndromes encountered in the ED as well as the appropriate strategies and instruments, which can be utilized to support the clinical decision matrix and improve outcomes. 


\section{Delirium}

Delirium is defined as an acute change in cognition that cannot be better accounted for by pre-existing dementia. It is characterized by the acute onset of inattention, disorganized thinking, altered level of consciousness and perceptual disturbances. It is traditionally classified into three subtypes: hypoactive delirium (characterized by decreased psychomotor activity), hyperactive delirium (increased psychomotor activity with restlessness and agitation) and mixed delirium (characterized by fluctuating levels of psychomotor activity). ${ }^{12}$ The vast majority of the patients in the ED who exhibit delirium have a hypoactive or mixed subtype. ${ }^{13}$

It is estimated that approximately $10 \%$ of all older patients in the ED meet the criteria for delirium. ${ }^{13-15}$ The prognostic importance of delirium is well established. A number of studies have shown that it is associated with longer hospital admissions, ${ }^{16,17}$ and an increased mortality. ${ }^{18,19}$ Several studies have established the negative consequences of delirium in the ED setting wherein delirium has been linked to higher mortality rates at 3-, ${ }^{15}$ and 6-month follow-up. ${ }^{20}$ The Society for Academic Emergency Medicine Geriatrics Task Force has recently recommended that screening for delirium in the ED ought to be one of the key quality indicators in the delivery of acute geriatric care. ${ }^{21}$ The evolution of delirium represents a complex interplay between precipitating factors and an underlying vulnerability to developing delirium. Dementia is a clearly established vulnerability factor, ${ }^{22-25}$ as is age, ${ }^{26}$ alcohol abuse, ${ }^{25}$ visual impairment, ${ }^{22}$ and high levels of coexisting comorbidities. ${ }^{25}$ Precipitating factors are important to recognize and include infection, ${ }^{23,26,27}$ dehydration, ${ }^{22}$ electrolyte imbalances, ${ }^{17}$ drug withdrawal, ${ }^{28}$ and organ failure. ${ }^{17}$
Medications are also common precipitants for delirium with anticholinergic drugs, ${ }^{29,30}$ benzodiazepines, ${ }^{31}$ and narcotic agents $^{23}$ being the commonest offenders. The risk factors for delirium are summarized in Table 1.

Unfortunately despite the fact that delirium and its negative consequences have been well established, physicians and nurses in ED frequently overlook it, with $76 \%-84 \%$ of cases missed in some studies. ${ }^{14,20}$ The consequences of failing to recognize delirium can have prognostic implications, with higher 3 month mortality rates in those in whom the diagnosis was missed compared to those in whom delirium was identified $(30.8 \%$ vs $11.8 \%) .{ }^{32}$ We have previously evaluated the knowledge and attitudes of doctors (Medical, Surgical, and ED physicians) toward assessing cognition in older patients. ${ }^{33}$ Whilst the majority of ED doctors felt screening for cognition was important (78\%), almost one-third felt they lacked the relevant expertise to perform cognitive screening. ${ }^{33}$ Other factors cited as limiting the potential to accurately assess cognition were lack of an established and environmentally suitable screening instrument, lack of privacy, too much noise and time constraints. ${ }^{33}$ The most widely used assessment tool for the identification of delirium is the Confusion Assessment Method (CAM) which consists of four features: 1) acute onset of mental status changes and a fluctuating course, 2) inattention, 3) disorganized thinking, and 4) altered level of consciousness. ${ }^{34} \mathrm{~A}$ patient should have features of 1 and 2 , and either feature 3 or 4 to meet the criteria for delirium. CAM has high sensitivity (94\%-100\%) and specificity (90\%-95\%) in hospitalized patients. ${ }^{34} \mathrm{CAM}$ has also been validated for use in the ED with a similarly high sensitivity, specificity, and good interobserver reliability. ${ }^{35}$ The major limitation of

Table I Summary of risk factors for delirium

\begin{tabular}{|c|c|c|c|c|}
\hline \multicolumn{5}{|c|}{ Risk factors for delirium } \\
\hline Patient-related risks & Illness-related risks & $\begin{array}{l}\text { Environmental- } \\
\text { related risks }\end{array}$ & $\begin{array}{l}\text { Intervention- } \\
\text { related risks }\end{array}$ & $\begin{array}{l}\text { Medication-related } \\
\text { risks }\end{array}$ \\
\hline Age $\geq 70$ years & Illness severity & Social isolation & Perioperative & Polypharmacy \\
\hline $\begin{array}{l}\text { Pre-existing cognitive } \\
\text { impairment }\end{array}$ & Dehydration & Sensory extremes & $\begin{array}{l}\text { Types of surgery, eg, } \\
\text { hip, cardiac }\end{array}$ & $\begin{array}{l}\text { Drug/alcohol } \\
\text { dependence }\end{array}$ \\
\hline $\begin{array}{l}\text { Previous episode of } \\
\text { delirium }\end{array}$ & $\begin{array}{l}\text { Infection, eg, urinary } \\
\text { tract infection }\end{array}$ & Visual deficit & Duration of operation & Benzodiazepine use \\
\hline CNS disorder & Fracture & Hearing deficit & Catheterization & Nicotine withdrawal \\
\hline $\begin{array}{l}\text { Increased BBB } \\
\text { permeability }\end{array}$ & Hypothermia/fever & Immobility & Emergency procedure & $\begin{array}{l}\text { Addition of } \geq 3 \text { new } \\
\text { medications }\end{array}$ \\
\hline Poor nutritional status & Hypoxia & Use of restraints & & Psychoactive drug use \\
\hline \multirow[t]{4}{*}{$\begin{array}{l}\text { Number and severity of } \\
\text { comorbid illnesses }\end{array}$} & $\begin{array}{l}\text { Metabolic/electrolyte } \\
\text { disturbances, eg, low sodium }\end{array}$ & Novel environment & & $\begin{array}{l}\text { Certain drugs, eg, } \\
\text { anticholinergics }\end{array}$ \\
\hline & Pain & Stress & & \\
\hline & Organ insufficiency & & & \\
\hline & Burns & & & \\
\hline
\end{tabular}

Abbreviations: CNS, central nervous system; BBB, blood-brain barrier. 
CAM is that it takes approximately 10 minutes to perform and this restricts its general clinical use in a busy ED environment. The CAM for the intensive care unit (CAM-ICU) is a modified version of CAM, which takes less than 2 minutes to perform. It has been validated in both the ICU and ED setting with excellent sensitivity, specificity, and interrater reliability in ICU patients. ${ }^{36,37}$ It uses similar features as the CAM, but reorders features 3 and 4 and alters feature 1 as follows: 1) acute onset of mental status changes or a fluctuating course, 2) inattention, 3) altered level of consciousness, and 4) disorganized thinking.

Once delirium has been identified it is necessary to establish the etiology. A detailed history (and collateral/informant history where available) and physical examination is crucial. One should focus in particular on signs and symptoms of infection, which is one of the common precipitants of delirium, but also carefully review the patient's medications, as well as taking care to identify a history of alcohol and benzodiazepine misuse. Other commonly missed precipitants for delirium in older ED patients are urinary retention, constipation, and pain in an individual who is unable to articulate it clearly. Basic biochemical markers can identify the etiology in many cases, especially electrolyte disturbances, uremia, and liver failure. An arterial blood gas can be useful if hypercapnia is suspected in patients with a history of chronic obstructive pulmonary disease. A urinalysis in all delirious patients is mandatory as urinary tract infections are one of the commonest causes of delirium. A chest X-ray should be performed in the majority of delirious patients to identify pneumonia. A lumbar puncture might be performed in selected patients in whom personality changes or delirium could be explained by meningitis or by encephalitis. Performing computed tomography of the brain should also be performed in selected patients, particularly those with a low level of consciousness, a history of falls, or focal neurological deficits. ${ }^{38}$

The nonpharmacological management of delirium utilizes a variety of strategies including reorientation of patients with the use of visible cues such as clocks and calendars in the patient's room, restricting the use of physical restraints such as urinary catheters, and avoiding interruptions to the normal sleep-wake cycle. The role of such nonpharmacological methods has been shown to be effective in the management of postoperative patients. ${ }^{39}$ Antipsychotic medications are favored to benzodiazepines in agitated patients with delirium. Haloperidol has been shown to be effective in improving symptom severity in delirium compared to placebo. ${ }^{40}$ However, atypical antipsychotics have also been shown to be effective, ${ }^{41}$ with a lower incidence of extrapyramidal side effects. ${ }^{42}$ While there is a role for the use of benzodiazepines in the setting of alcohol withdrawal, they have a significant side effect profile, including falls, worsening of delirium, and oversedation, ${ }^{43}$ and are therefore best avoided.

Delirium is not a static clinical entity, and the associated symptoms often fluctuate throughout the day and indeed often throughout the hour. Patients at risk of delirium, but who do not have delirium on initial assessment should have regular (at least every 2 hours) screening for the development of delirium while having care in the ED. Instruments such as the Delirium Risk Assessment Tool have been developed to identify patients at risk of developing delirium, but in reality, all older patients in the ED are at substantive risk and should be screened..$^{44}$

\section{Dementia}

The prevalence of dementia increases with age. It is estimated that $<1 \%$ of the people $<65$ years have dementia with this figure rising from $3 \%$ to $11 \%>65$ years, and it is present in approximately one-third of people $>85$ years. ${ }^{45-48}$ In the ED setting, it is estimated that up to $26 \%$ of older patients have some form of cognitive impairment. ${ }^{49}$ Furthermore, the majority of patients $(60 \%)$ who screen positive for cognitive impairment in the ED setting have no prior history of dementia. ${ }^{49}$ Hence, screening for cognitive impairment in the ED provides an opportunity to diagnose dementia when the diagnosis has not been suspected in the community or outpatient setting. In 2009, the worldwide health costs for dementia were US $\$ 422$ billion, which represented a 34\% rise compared with figures from 2005. ${ }^{50}$ Recognizing dementia in the ED setting is important as patients with cognitive impairment are more likely to represent to the ED, following discharge ${ }^{51}$ and are less likely to understand or follow discharge instructions. ${ }^{52,53}$ Nevertheless, the pick-up rate for detecting cognitive impairment by ED doctors is poor, at just $70 \%$ in one study. ${ }^{49}$ The lack of consensus on what constitutes an appropriate screening tool for cognitive impairment in the ED setting is probably one of the primary reasons for the low rate of detection of dementia in this environment.

A variety of screening tools for detecting cognitive impairment exist but not all of them are suitable for the ED environment due to time constraints. The Mini Mental State Examination (MMSE) is a 30-point assessment tool ${ }^{54}$ that has become a common instrument for screening and monitoring the progression of dementia. ${ }^{55}$ It takes approximately 8 minutes to perform, ${ }^{56}$ which is the main limiting factor for use in the ED environment. A score of 23 or less is the 
cut-off for detecting significant cognitive impairment. ${ }^{57}$ One of the other important limitations of the MMSE is that educational attainment, language and cultural barriers impact upon scores. ${ }^{58,59}$ Furthermore, the MMSE is less sensitive for detecting non-Alzheimer's dementia, including vascular, frontotemporal, and subcortical dementias, as it does not rigorously assess for frontal, executive, or visuospatial dysfunction. ${ }^{60,61}$

The Six-Item Screener (SIS) consists of three orientation questions (day, month, and year) and a three-item recall task. ${ }^{62}$ A score of 4 or less indicates a positive screen for cognitive impairment. ${ }^{63}$ In one study, $42 \%$ of the older adults $>65$ years in the ED screened positive for cognitive impairment using SIS. ${ }^{64}$ In one study the SIS was $63 \%$ sensitive and $81 \%$ specific for detecting cognitive impairment in the ED setting in patients who had already screened positive for significant cognitive deficits using the MMSE. ${ }^{52}$ The Clock Drawing Test is a screening instrument for detecting visuospatial, constructional praxis, and executive dysfunction. It has a high sensitivity (85\%) and specificity (85\%) for detecting cognitive impairment. ${ }^{65}$ It also has a high interrater and test-retest reliability ${ }^{65}$ and is quick and easy to perform in the ED setting. It is also relatively independent from other factors such as educational attainment, language, or cultural factors. ${ }^{66}$ The limitations of the Clock Drawing Test are that there are at least 15 different scoring systems for the screening tool, ${ }^{67,68}$ it is poor at distinguishing between various dementia subtypes, ${ }^{69,70}$ and that it is less useful in picking up mild cognitive impairment. ${ }^{71}$

Ideally, an instrument that briefly screens for both dementia and delirium concurrently would be useful. The 4AT is a screening instrument designed for rapid initial assessment of delirium and cognitive impairment, and is currently undergoing a multisite ED validation study. ${ }^{72}$ The 4-item Abbreviated Mental Test assesses the patient for level of alertness, inattention, and for an acute fluctuating change in cognition. ${ }^{72}$

\section{Falls and syncope}

Between $30 \%$ and $40 \%$ of community-dwelling people over the age of 65 years fall each year, ${ }^{73-78}$ increasing to about $50 \%$ for those 80 years and older. ${ }^{79,80}$ A history of previous falls in the past year is a predictor of future falls. Between 5\% and $10 \%$ of falls among community-dwelling older people result in major injuries ${ }^{78,81}$ and the risk of major injuries is even higher in nursing home residents $(10 \%-30 \%){ }^{82,83}$ Falls accounted for $62 \%$ of nonfatal injuries leading to US ED presentations in older adults, ${ }^{84}$ whilst $5 \%$ of falls in older persons will lead to hospitalization. ${ }^{85}$ Moreover falls are an independent risk factor for nursing home placement. ${ }^{86}$ Approximately, 2\% of older patients presenting to the ED with a fall will ultimately die from the complications of the fall. ${ }^{87}$

The assessment of an older patient in the ED who has presented with a fall involves a targeted history and examination in order to identify the etiology and any injurious complications. Most falls in older patients are multifactorial and usually have some or all of the following three risk factors: 1) Cognitive impairment, 2) Orthostatic hypotension, and 3) an underlying gait or balance disorder. Every older patient presenting to the ED with falls should be assessed for these three parameters. Physicians should inquire into the context of the fall in relation to the location and activity of the patient at the time of the event, and establish if any prodromal symptoms were present such as presyncope or loss of consciousness, which may indicate a cardiac or orthostatic hypotensive etiology. The historian should identify the presence of certain chronic diseases (eg, Parkinson's disease or an established neurological deficit from a prior stroke) or pain from chronic musculoskeletal conditions that might increase the risk of falls. A history of alcohol excess is a risk factor for falls. ${ }^{88}$ Furthermore, a careful review of the patient's medications is essential. In particular, attention should be paid to newly prescribed medications or recent dose increments. The commonest offending agents associated with an increased risk of falls include benzodiazepines, antidepressants, hypnotics, neuroleptics, and antihypertensive agents (vasodilators and diuretics in particular). ${ }^{89} \mathrm{~A}$ targeted physical examination should involve examining for any evidence of head injury or orthopedic injuries. Checking the patient's lying and standing blood pressure may quickly rule in orthostatic hypotension as the cause of the fall. One should take note of any evidence of visual or hearing impairment, examine the lower limbs for evidence of neuropathy or weakness, and inspect the patient's feet and footwear. Finally a physical assessment should include a brief gait and balance assessment. Common factors that might prompt medical referral for further assessment include the following: recurrent falls, inability to get up after a fall, or inability to mobilize in the ED.

The Timed Up and Go test is probably the best known and most feasible means of assessing for gait disorders that might put the patient at risk of future falls. It assesses both dynamic and static balance, and involves recording the time taken for a person to rise from a chair, walk 3 meters, turn around, walk back to the chair, and sit down. Poor Timed $\mathrm{Up}$ and Go performance is associated with poor muscle 
strength, slow gait speed, fear of falling, physical inactivity, and impairments in basic and instrumental activities of daily living. ${ }^{90,91}$ As of now there are few reliable or widely accepted risk stratification instruments available for application in the ED setting to identify patients at an increased risk of falls in the short-term. ${ }^{92}$ However, it is probably reasonable that at the very least patients with cognitive impairment and falls in the ED should receive 1:1 supervision to minimize the risk of falls while in the department.

In recent years, efforts have been made in certain centers to establish dedicated syncope units, in an effort to provide rapid access for patients to expert evaluation of falls, in both the inpatient and outpatient setting. In the UK for instance, one center published the performance data in its own syncope and falls facility in comparison with 13 peer hospitals. ${ }^{93}$ The unit recorded up to 2,400 consultant episodes per year with a projected saving of 6,616 bed days, which equated to 18 occupied beds in the hospital per year. ${ }^{93}$ Furthermore, the average length of stay in the hospital for patients admitted with falls averaged just 2.4 days vs 8.6 days at peer sites, which in turn led to a significant cost saving for the center. ${ }^{93}$ The growth of such dedicated falls units provide an important care pathway for ED physicians to utilize to facilitate rapid assessment of older patients presenting with falls and avoid unnecessary hospital admissions where appropriate; however, many of the risk factors for falls can be identified and targeted interventions initiated when the patient is in the ED.

\section{Frailty}

Frailty is a biologic syndrome of decreased reserve and resistance to stressors, resulting from cumulative declines across multiple physiologic systems, and causing vulnerability to adverse outcomes. ${ }^{94}$ It ought to be distinguished from disability. Frailty is highly prevalent with advancing age and is a strong predictor of adverse outcomes including falls, mortality, institutionalization, and hospitalization. ${ }^{94-97}$ It is characterized by the presence of the following: unintentional weight loss, impaired grip strength, self-reported exhaustion, slow gait speed, and low physical activity. ${ }^{98}$ In one study patients who met the criteria for frailty had a sixfold increased risk of death over 3 years, ${ }^{98}$ and it is a strong predictor of serious adverse outcomes during the first 30 days following discharge from ED. ${ }^{99}$ It is in this context that frailty is being increasingly recognized as an important geriatric syndrome which is independently predictive of adverse outcomes. In this regard it is important that frailty is recognized by treating physicians.
In recent years efforts have been made to utilize various frailty prediction models to identify patients at risk, and thereby referring such patients to geriatricians in an effort to improve outcomes. To date the use of frailty rating scales within the ED setting have had poor predictive value in determining adverse outcomes. ${ }^{100,101}$ Frailty, while a very important clinical paradigm, largely remains a diagnosis or descriptor most suited to community dwelling older persons, as its application and utility within the acute setting still remain unclear.

\section{Polypharmacy}

A potentially inappropriate medication (PIM) is defined as a medication where the potential risk from its use outweighs the benefits. ${ }^{102}$ PIMs are associated with an increased risk of falls in older patients ${ }^{103}$ and unnecessary health care expenditure. ${ }^{104}$ Two of the most widely used methods in current practice to identify PIMs are the Beers criteria ${ }^{105}$ and the Screening Tool of Older Persons' Prescriptions (STOPP) criteria. ${ }^{106}$ These tools are particularly useful when applied to the older patient in the ED and provide an opportunity to intervene and discontinue any inappropriately prescribed medications. Common PIMs identified by the Beers and STOPP criteria include antipsychotics, benzodiazepines, antiplatelets, antiepileptics, and tricyclic antidepressants. The rate of PIMs is particularly high in nursing home residents $\left(59.8 \%\right.$ in one study),${ }^{107}$ when compared with the primary care setting $(18.3 \%) .{ }^{108}$ Therefore, a particular focus on polypharmacy needs to be taken in nursing home residents presenting to the ED. We have previously reported that when either the Beers (2012) or STOPP criteria are applied, there is an association between prescribing of PIMs and ED attendance in over $30 \%$ of older nursing home residents. ${ }^{109}$

\section{Recognizing older patients in need of comprehensive geriatric assessment}

Older patients discharged from the ED and the acute medical units (AMU) frequently experience adverse health outcomes. In one study, $58 \%$ of older patients discharged from the AMU subsequently re-presented and $29 \%$ died during a follow-up period of 1 year. ${ }^{110}$ It is proposed that older patients presenting to the AMU or ED may benefit from comprehensive geriatric assessment which is well recognized to be associated with improved outcomes for patients (reduced mortality, reduced need for long-term care, reduced inpatient length of stay) compared with standard medical therapy when delivered 
in specialist geriatric wards. ${ }^{111}$ This geriatric specialist intervention, commonly referred to as Interface Geriatrics, targets older frail patients in the acute setting, with the aim of reducing adverse outcomes and readmissions. Common interventions made by specialist geriatric services include drug reviews, referral to community services, falls management, capacity assessments, end of life care, and medical care. Table 2 outlines the key components of comprehensive geriatric assessment. In one recently published study in the UK, 433 patients over the age of 70 discharged within 72 hours of admission to the AMU, who were categorized as being at risk using the Identification of Seniors at Risk (ISAR) tool, were randomized to receive standard medical followup or specialist geriatric review prior to discharge. Ninety days after randomization, there was no difference between the two groups in either the primary outcome (days spent at home) or secondary outcomes (mortality, institutionalization, dependency, mental wellbeing, quality of life, and health and social care resource uses). ${ }^{112}$ These negative results may be explained by the limited nature of the ISAR screening tool, especially with regards its specificity (ie, ISAR), and the fact that the geriatric liaison service and intervention was nonspecific and ill defined. The ISAR screening tool is a sixitem, self-administered questionnaire which was developed to identify seniors in an ED setting at high risk of subsequent functional decline (including institutionalization or death). ${ }^{13}$ A key element of comprehensive geriatric assessment is that the environment in which it is delivered is gerontologically attuned. There is very limited evidence that liaison

Table 2 Components of comprehensive geriatric assessment

Key elements of comprehensive geriatric assessment
Medical assessment
Problem list
Comorbidities
Medications
Nutritional assessment
Functional assessment
Basic activities of daily living
Instrumental activities of daily living
Gait and balance assessment
Exercise/activity assessment
Psychological assessment
Cognitive status
Assessment of mood
Social assessment
Informal social support
Environmental assessment
Care resource eligibility/financial assessment
Home safety
Access to transport facilities

geriatrician consultation services in the absence of the other essential components of comprehensive geriatric assessment (gerontological nursing, physiotherapy, occupational therapy, speech, and language therapy, and clinical nutrition) has any impact on patient outcomes. ${ }^{114}$

In 2014, Conroy et $\mathrm{a}^{115}$ published a study evaluating the role of comprehensive geriatric assessment in the ED. The Emergency Frailty Unit (EFU) was a designated 8-12 bedded ward area within the main ED with medical input provided by a consultant geriatrician and full multidisciplinary team support. A care pathway within the ED was established whereby frail older patients were identified who were likely to be discharged home within 24 hours. The study evaluated the intervention of care within the EFU compared with usual care (Emergency Decision Unit run by emergency physicians). The EFU was shown to be effective at reducing admission rates (relative risk [RR] 0.88, 95\% confidence interval [CI] 0.81-0.95) and reducing hospital readmissions in people aged $>85$ years who were discharged from the ED. ${ }^{115}$ Another model of liaison geriatric assessment has been described in the ED setting in patients not yet admitted to hospital. The Geriatric ED innovations (GEDI) project aimed to train ED nurses in geriatric assessment and care coordination skills. All older patients in the ED aged over 65 years with an ISAR score $>2$ were referred to the on-site GEDI liaison nurse. Referred patients were screened for delirium using CAM, had a falls risk assessment, brief cognitive evaluation, screened for caregiver strain and had a functional status assessment. The results of the intervention were recently published. Patients who were assessed by the liaison service had a lower admission rate to hospital than patients who did not (44\% vs $60 \%$ ), with no increased risk of ED revisits. Limitations of the intervention were that it did not shorten length of hospital stay, and patients referred to the GEDI service had a longer ED stay (1.1 hours); although some of these effects may be offset by the positive effects. The challenge of implementing such strategies was evident in that only $20 \%$ of patients eligible for assessment were reviewed due to the absence of the service out-of-hours. ${ }^{116}$

The increasing recognition of the potential benefits of comprehensive geriatric assessment in older patients is underlined by recently published data evaluating the role of Acute Geriatric Units. These dedicated geriatric units are specifically designed to prevent functional decline and related complications in older patients admitted to hospital who are acutely unwell. In a meta-analysis of 13 randomized control trials published in 2012, acute geriatric unit care was associated with fewer falls, less delirium, less functional decline at 
discharge, shorter hospital stay, fewer discharges to nursing homes, lower costs, and more home discharges, but no impact on mortality or hospital readmission. ${ }^{117}$

The ideal model for the delivery of timely, comprehensive, gerontologically attuned care to older patients in the acute setting is not yet defined. What appears clear from the evidence to date is that an age-friendly acute care environment, in which all healthcare staff are appropriately trained to deliver care to older people, is likely to improve outcomes in this patient group, whereas a liaison geriatric consultation service in isolation is likely to be inadequate.

\section{The limitations of the ED environment}

An integral part of comprehensive geriatric assessment and its success in inpatient care has been its delivery within specifically designated wards, by well-trained health care staff. A major challenge is in how we create age-friendly environments in the ED. Most EDs have their infrastructure developed to manage critical care and trauma patients which render them largely inappropriate for delivering acute care to older patients, many of whom may have coexisting dementia or delirium. This is supported by older patients' own expressed perceptions that ED staff are frequently inattentive to their questions or needs. ${ }^{118}$ The nature of the busy, noisy ED environment is not conducive for the management of an acutely unwell older patient with delirium or dementia, in which artificial lighting impairs the normal sleep-wake cycle. It is not uncommon for patients to remain in hospital trolleys unsuitably designed for the prevention of pressure ulcers in immobile patients, while waiting diagnostic investigations or placement in acute medical beds.

It has been suggested that the introduction of age-friendly measures in EDs may improve the care of older patients through a cultural change in the department that embraces the difficulties and challenges particular to the delivery of acute care in older patients in the emergency setting. ${ }^{3}$ This can be achieved through the introduction of care pathways and training health care staff in the management of common geriatric syndromes. The geographical design of the ED is also important. It has been suggested that future EDs or renovations to present EDs need to be mindful of the special needs of older patients who are acutely unwell. This requires the design or modification of EDs such that there is access to natural lighting, the presence of support rails and floor lighting on the aisles to facilitate people who are less mobile and hence reduce falls risk, provide visual aids and hearing devices where necessary, and provide pressurerelieving mattresses for patients who require them. ${ }^{3}$

\section{Conclusion}

Older patients in the modern ED make up an increasing number of presentations. They are a patient population who provide unique challenges to ED physicians given the frequent complexity of their background medical conditions, the high prevalence of delirium and/or dementia and polypharmacy. The American Geriatric Society and the American College of American Physicians have recently published guidelines in relation to geriatric care in the ED setting. ${ }^{119}$ The purpose of these guidelines is to outline and standardize best practice to improve the care of older patients. These guidelines create a template for staffing, equipment, education, policies and procedures, follow-up care, and performance improvement measures. Specifically, the guidelines examine the means by which institutions can effectively allocate health care resources, optimize admission and readmission rates; while minimizing iatrogenic complications. The paper has described the ED as a crossroads between inpatient and community care of older patients, which provides an opportunity to direct appropriate follow-up, thereby preventing re-presentations to ED and unnecessary hospital admissions.

In this review we have identified the common pitfalls in the management of older patients in the ED, with particular focus on the instruments and tools that can be employed to improve outcomes. It is vital that a modern-day ED recognizes the importance of fostering an age-friendly environment so that the acute care of older patients is optimal. To this end, each ED must introduce its own care pathways and strategies for managing the common geriatric syndromes outlined in this paper.

\section{Disclosure}

The authors report no conflicts of interest in this work.

\section{References}

1. Chenore T, Pereira Gray DJ, Forrer J, Wright C, Evans PH. Emergency hospital admissions for the elderly: insights from the Devon Predictive Model. J Public Health (Oxf). 2013;35(4):616-623.

2. European Commission. The 2012 Ageing Report. Brussels: European Commission. Available from: http://ec.europa.eu/economy_finance/ publications/european_economy/2012/pdf/ee-2012-2_en.pdf. Accessed June 9, 2015

3. Hwang U, Morrison RS. The geriatric emergency department. $J$ Am Geriatr Soc. 2007;55(11):1873-1876.

4. www.parliament.uk [homepage on the Internet]. Health Committee: Written evidence from the British Geriatrics Society (ETWP 26); 2011. Available from http://www.publications.parliament.uk/pa/cm201213/ cmselect/cmhealth/6/6vw03.htm. Accessed June 9, 2015.

5. Denman SJ, Ettinger WH, Zarkin BA, Coon PJ, Casani JA. Short-term outcomes of elderly patients discharged from an emergency department. J Am Geriatr Soc. 1989;37(10):937-943. 
6. Round A, Crabb T, Buckingham K, et al. Six month outcomes after emergency admission of elderly patients to a community or a district general hospital. Fam Pract. 2004;21(2):173-179.

7. Strange GR, Chen EH, Sanders AB. Use of emergency departments by elderly patients: projections from a multicenter data base. Ann Emerg Med. 1992;21(7):819-824.

8. Singal BM, Hedges JR, Rousseau EW, et al. Geriatric patient emergency visits. Part I: comparison of visits by geriatric and younger patients. Ann Emerg Med. 1992;21(7):802-807.

9. Aminzadeh F, Dalziel WB. Older adults in the emergency department: a systematic review of patterns of use, adverse outcomes, and effectiveness of interventions. Ann Emerg Med. 2002;39(3):238-247.

10. Strange GR, Chen EH. Use of emergency departments by elder patients: a five-year follow-up study. Acad Emerg Med. 1998;5(12):1157-1162.

11. Kennelly SP, Drumm B, Coughlan T, Collins R, O’Neill D, RomeroOrtuno R. Characteristics and outcomes of older persons attending the emergency department: a retrospective cohort study. QJM. 2014;107(12):977-987.

12. Meagher DJ, Trzepacz PT. Motoric subtypes of delirium. Semin Clin Neuropsychiatry. 2000;5(2):75-85.

13. Han JH, Zimmerman EE, Cutler N, et al. Delirium in older emergency department patients: recognition, risk factors, and psychomotor subtypes. Acad Emerg Med. 2009;16(3):193-200.

14. Hustey FM, Meldon SW, Smith MD, Lex CK. The effect of mental status screening on the care of elderly emergency department patients. Ann Emerg Med. 2003;41(5):678-684.

15. Lewis LM, Miller DK, Morley JE, Nork MJ, Lasater LC. Unrecognized delirium in ED geriatric patients. Am J Emerg Med. 1995;13(2): $142-145$.

16. Ely EW, Gautam S, Margolin R, et al. The impact of delirium in the intensive care unit on hospital length of stay. Intensive Care Med. 2001;27(12):1892-1900.

17. Francis J, Martin D, Kapoor WN. A prospective study of delirium in hospitalized elderly. JAMA. 1990;263(8):1097-1101.

18. Ely EW, Shintani A, Truman B, et al. Delirium as a predictor of mortality in mechanically ventilated patients in the intensive care unit. JAMA. 2004;291(14):1753-1762.

19. McCusker J, Cole M, Abrahamowicz M, Primeau F, Belzile E. Delirium predicts 12-month mortality. Arch Intern Med. 2002;162(4):457-463.

20. Han JH, Shintani A, Eden S, et al. Delirium in the emergency department: an independent predictor of death within 6 months. Ann Emerg Med. 2009;56(3):244-252. e1.

21. Terrell KM, Hustey FM, Hwang U, Gerson LW, Wenger NS, Miller DK. Quality indicators for geriatric emergency care. Acad Emerg Med. 2009;16(5):441-449.

22. Inouye SK, Viscoli CM, Horwitz RI, Hurst LD, Tinetti ME. A predictive model for delirium in hospitalized elderly medical patients based on admission characteristics. Ann Intern Med. 1993;119(6):474-481.

23. Schor JD, Levkoff SE, Lipsitz LA, et al. Risk factors for delirium in hospitalized elderly. JAMA. 1992;267(6):827-831.

24. Elie M, Cole MG, Primeau FJ, Bellavance F. Delirium risk factors in elderly hospitalized patients. J Gen Intern Med. 1998;13(3):204-212.

25. Pompei P, Foreman M, Rudberg MA, Inouye SK, Braund V, Cassel CK. Delirium in hospitalized older persons: outcomes and predictors. J Am Geriatr Soc. 1994;42(8):809-815.

26. Jitapunkul S, Pillay I, Ebrahim S. Delirium in newly admitted elderly patients: a prospective study. QJ Med. 1992;83(300):307-314.

27. Rockwood K. Acute confusion in elderly medical patients. JAm Geriatr Soc. 1989;37(2):150-154.

28. Rahkonen T, Makela H, Paanila S, Halonen P, Sivenius J, Sulkava R. Delirium in elderly people without severe predisposing disorders: etiology and 1-year prognosis after discharge. Int Psychogeriatr. 2000;12(4): 473-481.

29. Caeiro L, Ferro JM, Claro MI, Coelho J, Albuquerque R, Figueira ML. Delirium in acute stroke: a preliminary study of the role of anticholinergic medications. Eur J Neurol. 2004;11(10):699-704.
30. Tune LE, Egeli S. Acetylcholine and delirium. Dement Geriatr Cogn Disord. 1999;10(5):342-344.

31. Foy A, O’Connell D, Henry D, Kelly J, Cocking S, Halliday J. Benzodiazepine use as a cause of cognitive impairment in elderly hospital inpatients. J Gerontol A Biol Sci Med Sci. 1995;50(2):M99-M106.

32. Kakuma R, du Fort GG, Arsenault L, et al. Delirium in older emergency department patients discharged home: effect on survival. J Am Geriatr Soc. 2003;51(4):443-450.

33. Kennelly SP, Morley D, Coughlan T, Collins R, Rochford M, O’Neill D. Knowledge, skills and attitudes of doctors towards assessing cognition in older patients in the emergency department. Postgrad Med J. 2012;89(1049):137-141.

34. Inouye SK, van Dyck CH, Alessi CA, Balkin S, Siegal AP, Horwitz RI. Clarifying confusion: the confusion assessment method. A new method for detection of delirium. Ann Intern Med. 15 1990;113(12):941-948.

35. Monette J, Galbaud du Fort G, Fung SH, et al. Evaluation of the Confusion Assessment Method (CAM) as a screening tool for delirium in the emergency room. Gen Hosp Psychiatry. 2001;23(1):20-25.

36. Ely EW, Margolin R, Francis J, et al. Evaluation of delirium in critically ill patients: validation of the Confusion Assessment Method for the Intensive Care Unit (CAM-ICU). Crit Care Med. 2001;29(7): 1370-1379.

37. Han JH, Wilson A, Graves AJ, et al. Validation of the Confusion Assessment Method for the Intensive Care Unit in older emergency department patients. Acad Emerg Med. 2014;21(2):180-187.

38. Naughton BJ, Moran M, Ghaly Y, Michalakes C. Computed tomography scanning and delirium in elder patients. Acad Emerg Med. 1997; 4(12):1107-1110.

39. Marcantonio ER, Flacker JM, Wright RJ, Resnick NM. Reducing delirium after hip fracture: a randomized trial. JAm Geriatr Soc. 2001; 49(5):516-522.

40. $\mathrm{Hu} \mathrm{H}$, Deng W, Yang H. A prospective random control study comparison of olanzapine and haloperidol in senile delirium. Chongqing Med J. 2004;8:1234-1237.

41. Lee KU, Won WY, Lee HK, et al. Amisulpride versus quetiapine for the treatment of delirium: a randomized, open prospective study. Int Clin Psychopharmacol. 2005;20(6):311-314.

42. Ozbolt LB, Paniagua MA, Kaiser RM. Atypical antipsychotics for the treatment of delirious elders. J Am Med Dir Assoc. 2008;9(1): $18-28$.

43. Breitbart W, Marotta R, Platt MM, et al. A double-blind trial of haloperidol, chlorpromazine, and lorazepam in the treatment of delirium in hospitalized AIDS patients. Am J Psychiatry. 1996;153(2):231-237.

44. Care of Confused Hospitalised Older Persons. Delirium RiskAssessment Tool; Available from: http://www.aci.health.nsw.gov.au/chops/key-areas/ risk-and-prevention/delirium-risk-assessment-tool. Accessesd June 9, 2015.

45. Rocca WA, Bonaiuto S, Lippi A, et al. Prevalence of clinically diagnosed Alzheimer's disease and other dementing disorders: a doorto-door survey in Appignano, Macerata Province, Italy. Neurology. 1990;40(4):626-631.

46. Skoog I, Nilsson L, Palmertz B, Andreasson LA, Svanborg A. A population-based study of dementia in 85-year-olds. $N$ Engl J Med. 21, 1993;328(3):153-158

47. Lobo A, Launer LJ, Fratiglioni L, et al. Prevalence of dementia and major subtypes in Europe: a collaborative study of population-based cohorts. Neurologic Diseases in the Elderly Research Group. Neurology. 2000;54(11 Suppl 5):S4-S9.

48. Boustani M, Peterson B, Hanson L, Harris R, Lohr KN. Screening for dementia in primary care: a summary of the evidence for the US Preventive Services Task Force. Ann Intern Med. 2003;138(11):927-937.

49. Hustey FM, Meldon SW. The prevalence and documentation of impaired mental status in elderly emergency department patients. Ann Emerg Med. 2002;39(3):248-253.

50. Wimo A, Winblad B, Jonsson L. The worldwide societal costs of dementia: estimates for 2009. Alzheimers Dement. 2010;6(2):98-103. 
51. McCusker J, Healey E, Bellavance F, Connolly B. Predictors of repeat emergency department visits by elders. Acad Emerg Med. 1997;4(6):581-588.

52. Wilber ST, Carpenter CR, Hustey FM. The Six-Item Screener to detect cognitive impairment in older emergency department patients. Acad Emerg Med. 2008;15(7):613-616.

53. Wilber ST, Gerson LW, Terrell KM, et al. Geriatric emergency medicine and the 2006 Institute of Medicine reports from the Committee on the Future of Emergency Care in the US health system. Acad Emerg Med. 2006;13(12):1345-1351.

54. Folstein MF, Folstein SE, McHugh PR. "Mini-mental state". A practical method for grading the cognitive state of patients for the clinician. J Psychiatr Res. 1975;12(3):189-198.

55. O'Keeffe ST, Mulkerrin EC, Nayeem K, Varughese M, Pillay I. Use of serial Mini-Mental State Examinations to diagnose and monitor delirium in elderly hospital patients. J Am Geriatr Soc. 2005;53(5):867-870.

56. Swain DG, O'Brien AG, Nightingale PG. Cognitive assessment in elderly patients admitted to hospital: the relationship between the Abbreviated Mental Test and the Mini-Mental State Examination. Clin Rehabil. 1999;13(6):503-508.

57. Grace J, Amick MM. Cognitive screening of older adults. Med Health R I. 2005;88(1):8-11.

58. Tombaugh TN, McIntyre NJ. The mini-mental state examination: a comprehensive review. J Am Geriatr Soc. 1992;40(9):922-935.

59. Wood RY, Giuliano KK, Bignell CU, Pritham WW. Assessing cognitive ability in research: use of MMSE with minority populations and elderly adults with low education levels. J Gerontol Nurs. 2006;32(4): 45-54.

60. Blake H, McKinney M, Treece K, Lee E, Lincoln NB. An evaluation of screening measures for cognitive impairment after stroke. Age Ageing. 2002;31(6):451-456.

61. Bak TH, Rogers TT, Crawford LM, Hearn VC, Mathuranath PS, Hodges JR. Cognitive bedside assessment in atypical parkinsonian syndromes. J Neurol Neurosurg Psychiatry. 2005;76(3):420-422.

62. Callahan CM, Unverzagt FW, Hui SL, Perkins AJ, Hendrie HC. Six-item screener to identify cognitive impairment among potential subjects for clinical research. Med Care. 2002;40(9):771-781.

63. Wilber ST, Lofgren SD, Mager TG, Blanda M, Gerson LW. An evaluation of two screening tools for cognitive impairment in older emergency department patients. Acad Emerg Med. 2005;12(7):612-616.

64. Hirschman KB, Paik HH, Pines JM, McCusker CM, Naylor MD, Hollander JE. Cognitive impairment among older adults in the emergency department. West J Emerg Med. 2009;12(1):56-62.

65. Shulman KI. Clock-drawing: is it the ideal cognitive screening test? Int J Geriatr Psychiatry. 2000;15(6):548-561.

66. Borson S, Brush M, Gil E, et al. The clock drawing test: utility for dementia detection in multiethnic elders. J Gerontol A Biol Sci Med Sci. 1999;54(11):M534-M540.

67. Agrell B, Dehlin O. The clock-drawing test. Age Ageing. 1998;41 Suppl 3: iii41-iii45.

68. Philpot M. The clock-drawing test: a critique. Int Psychogeriatr. 2004; 16(3):251-256.

69. Cahn-Weiner DA, Williams K, Grace J, Tremont G, Westervelt H, Stern RA. Discrimination of dementia with Lewy bodies from Alzheimer disease and Parkinson disease using the clock drawing test. Cogn Behav Neurol. 2003;16(2):85-92.

70. Heinik J, Solomesh I, Raikher B, Lin R. Can clock drawing test help to differentiate between dementia of the Alzheimer's type and vascular dementia? A preliminary study. Int J Geriatr Psychiatry. 2002; 17(8):699-703

71. Seigerschmidt E, Mosch E, Siemen M, Forstl H, Bickel H. The clock drawing test and questionable dementia: reliability and validity. Int $J$ Geriatr Psychiatry. 2002;17(11):1048-1054.

72. Bellelli G, Morandi A, Davis DH, et al. Validation of the 4AT, a new instrument for rapid delirium screening: a study in 234 hospitalised older people. Age Ageing. 2014;43(4):496-502.
73. Thapa PB, Brockman KG, Gideon P, Fought RL, Ray WA. Injurious falls in nonambulatory nursing home residents: a comparative study of circumstances, incidence, and risk factors. J Am Geriatr Soc. 1996; 44(3):273-278.

74. Tinetti ME, Liu WL, Ginter SF. Mechanical restraint use and fall-related injuries among residents of skilled nursing facilities. Ann Intern Med. 1992;116(5):369-374

75. Nevitt MC, Cummings SR, Hudes ES. Risk factors for injurious falls: a prospective study. J Gerontol. 1991;46(5):M164-M170.

76. Rosado JA, Rubenstein LZ, Robbins AS, Heng MK, Schulman BL, Josephson KR. The value of Holter monitoring in evaluating the elderly patient who falls. J Am Geriatr Soc. 1989;37(5):430-434.

77. Tinetti ME. Clinical practice. Preventing falls in elderly persons. N Engl J Med. 2003;348(1):42-49.

78. Rubenstein LZ, Josephson KR. Falls and their prevention in elderly people: what does the evidence show? Med Clin North Am. 2006; 90(5):807-824.

79. Chang JT, Morton SC, Rubenstein LZ, et al. Interventions for the prevention of falls in older adults: systematic review and meta-analysis of randomised clinical trials. BMJ. 2004;328(7441):680.

80. Tinetti ME, Speechley M, Ginter SF. Risk factors for falls among elderly persons living in the community. N Engl J Med. 1988;319(26): 1701-1707.

81. Rubenstein LZ, Josephson KR. The epidemiology of falls and syncope. Clin Geriatr Med. 2002;18(2):141-158.

82. Nickens H. Intrinsic factors in falling among the elderly. Arch Intern Med. 1985;145(6):1089-1093.

83. Oliver D, Connelly JB, Victor CR, et al. Strategies to prevent falls and fractures in hospitals and care homes and effect of cognitive impairment: systematic review and meta-analyses. BMJ. 2007;334(7584):82.

84. Public health and aging: nonfatal injuries among older adults treated in hospital emergency departments - United States, 2001. MMWR Morb Mortal Wkly Rep. 2003;52(42):1019-1022.

85. American Geriatrics Society, British Geriatrics Society, and American Academy of Orthopaedic Surgeons Panel on Falls Prevention. Guideline for the prevention of falls in older persons. J Am Geriatr Soc. 2001;49(5):664-672.

86. Tinetti ME, Williams CS. Falls, injuries due to falls, and the risk of admission to a nursing home. N Engl J Med. 1997;337(18):1279-1284.

87. Sattin RW, Lambert Huber DA, DeVito CA, et al. The incidence of fall injury events among the elderly in a defined population. Am JEpidemiol. 1990;131(6):1028-1037.

88. Cawthon PM, Harrison SL, Barrett-Connor E, et al. Alcohol intake and its relationship with bone mineral density, falls, and fracture risk in older men. J Am Geriatr Soc. 2006;54(11):1649-1657.

89. Woolcott JC, Richardson KJ, Wiens MO, et al. Meta-analysis of the impact of 9 medication classes on falls in elderly persons. Arch Intern Med. 2009;169(21):1952-1960.

90. Bohannon RW. Reference values for the timed up and go test: a descriptive meta-analysis. J Geriatr Phys Ther. 2006;29(2):64-68.

91. Janssen HC, Samson MM, Meeuwsen IB, Duursma SA, Verhaar HJ. Strength, mobility and falling in women referred to a geriatric outpatient clinic. Aging Clin Exp Res. 2004;16(2):122-125.

92. Carpenter CR, Avidan MS, Wildes T, Stark S, Fowler SA, Lo AX. Predicting geriatric falls following an episode of emergency department care: a systematic review. Acad Emerg Med. 2014;21(10):1069-1082.

93. Kenny RA, O'Shea D, Walker HF. Impact of a dedicated syncope and falls facility for older adults on emergency beds. Age Ageing. 2002;31(4):272-275.

94. Campbell AJ, Buchner DM. Unstable disability and the fluctuations of frailty. Age Ageing. 1997;26(4):315-318.

95. Rockwood K, Stadnyk K, MacKnight C, McDowell I, Hebert R, Hogan DB. A brief clinical instrument to classify frailty in elderly people. Lancet. 1999;353(9148):205-206.

96. Speechley M, Tinetti M. Falls and injuries in frail and vigorous community elderly persons. J Am Geriatr Soc. 1991;39(1):46-52. 
97. Winograd $\mathrm{CH}$. Targeting strategies: an overview of criteria and outcomes. J Am Geriatr Soc. 1991;39(9 Pt 2):25S-35S.

98. Fried LP, Tangen CM, Walston J, et al. Frailty in older adults: evidence for a phenotype. J Gerontol A Biol Sci Med Sci. 2001;56(3): M146-M156.

99. Hastings SN, Purser JL, Johnson KS, Sloane RJ, Whitson HE. Frailty predicts some but not all adverse outcomes in older adults discharged from the emergency department. J Am Geriatr Soc. 2008;56(9):1651-1657.

100. Wou F, Gladman JR, Bradshaw L, Franklin M, Edmans J, Conroy SP. The predictive properties of frailty-rating scales in the acute medical unit. Age Ageing. 2013;42(6):776-781.

101. Edmans J, Bradshaw L, Gladman JR, et al. The Identification of Seniors at Risk (ISAR) score to predict clinical outcomes and health service costs in older people discharged from UK acute medical units. Age Ageing. 2013;42(6):747-753.

102. O'Mahony D, Gallagher PF. Inappropriate prescribing in the older population: need for new criteria. Age Ageing. 2008;37(2):138-141.

103. McMahon CG, Cahir CA, Kenny RA, Bennett K. Inappropriate prescribing in older fallers presenting to an Irish emergency department. Age Ageing. 2014;43(1):44-50.

104. Cahir C, Fahey T, Teeling M, Teljeur C, Feely J, Bennett K. Potentially inappropriate prescribing and cost outcomes for older people: a national population study. Br J Clin Pharmacol. 2010;69(5):543-552.

105. American Geriatrics Society 2012 Beers Criteria Update Expert Panel. American Geriatrics Society updated Beers Criteria for potentially inappropriate medication use in older adults. JAm Geriatr Soc. 2012; 60(4):616-631.

106. Gallagher P, Ryan C, Byrne S, Kennedy J, O'Mahony D. STOPP (Screening Tool of Older Person's Prescriptions) and START (Screening Tool to Alert doctors to Right Treatment). Consensus validation. Int J Clin Pharmacol Ther. 2008;46(2):72-83.

107. Ryan C, O'Mahony D, Kennedy J, Weedle P, Byrne S. Potentially inappropriate prescribing in an Irish elderly population in primary care. Br J Clin Pharmacol. 2009;68(6):936-947.

108. Ryan C, O’Mahony D, Kennedy J, et al. Potentially inappropriate prescribing in older residents in Irish nursing homes. Age Ageing. 2013;42(1):116-120.
109. Grace AR, Briggs R, Kieran RE, et al. A comparison of beers and STOPP criteria in assessing potentially inappropriate medications in nursing home residents attending the emergency department. $J \mathrm{Am}$ Med Dir Assoc. 2014;15(11):830-834.

110. Woodard J, Gladman J, Conroy S. Frail older people at the interface. JNHA. 2009;13((Suppl 1):S308).

111. Ellis G, Whitehead MA, Robinson D, O'Neill D, Langhorne P. Comprehensive geriatric assessment for older adults admitted to hospital: metaanalysis of randomised controlled trials. BMJ 2011;343:d6553.

112. Edmans J, Bradshaw L, Franklin M, Gladman J, Conroy S. Specialist geriatric medical assessment for patients discharged from hospital acute assessment units: randomised controlled trial. $B M J$. 2013;347:f5874.

113. McCusker J, Bellavance F, Cardin S, Trepanier S, Verdon J, Ardman O. Detection of older people at increased risk of adverse health outcomes after an emergency visit: the ISAR screening tool. J Am Geriatr Soc. 1999;47(10):1229-1237.

114. Deschodt M, Flamaing J, Haentjens P, Boonen S, Milisen K. Impact of geriatric consultation teams on clinical outcome in acute hospitals: a systematic review and meta-analysis. BMC Med. 2013;11:48.

115. Conroy SP, Ansari K, Williams M, et al. A controlled evaluation of comprehensive geriatric assessment in the emergency department: the 'Emergency Frailty Unit'. Age Ageing. 2014;43(1):109-114.

116. Aldeen AZ, Courtney DM, Lindquist LA, Dresden SM, Gravenor SJ. Geriatric emergency department innovations: preliminary data for the geriatric nurse liaison model. J Am Geriatr Soc. 2014;62(9): 1781-1785.

117. Fox MT, Persaud M, Maimets I, et al. Effectiveness of acute geriatric unit care using acute care for elders components: a systematic review and meta-analysis. J Am Geriatr Soc. 2012;60(12):2237-2245.

118. Nerney MP, Chin MH, Jin L, et al. Factors associated with older patients' satisfaction with care in an inner-city emergency department. Ann Emerg Med. 2001;38(2):140-145.

119. Carpenter CR, Bromley M, Caterino JM, et al. Optimal older adult emergency care: introducing multidisciplinary geriatric emergency guidelines from the American College of Emergency Physicians, American Geriatrics Society, Emergency Nurses Association, and Society for Academic Emergency Medicine. J Am Geriatr Soc. 2014;62(7):1360-1363.
Open Access Emergency Medicine

\section{Publish your work in this journal}

Open Access Emergency Medicine is an international, peer-reviewed, open access journal publishing original research, reports, editorials, reviews and commentaries on all aspects of emergency medicine. The manuscript management system is completely online and includes a very quick and fair peer-review system, which is all easy to use.

\section{Dovepress}

Visit http://www.dovepress.com/testimonials.php to read real quotes from published authors. 